\title{
Deficient Counseling on Physical Activity among Nephrologists
}

\author{
Cynthia Delgado Kirsten L. Johansen
}

Nephrology Section, San Francisco VA Medical Center, University of California, San Francisco, Calif., USA

\section{Key Words}

Deficient counseling $\cdot$ Exercise counseling practices . KDOQI guidelines $\cdot$ Nephrologists' counseling practices • Physical activity, nephrologists

\begin{abstract}
Background: An evaluation of exercise counseling practices among nephrologists in 2001 demonstrated few clinicians assessing patients' levels of physical activity (PA) and counseling to increase activity. Recent Kidney Disease Outcomes Quality Initiative (KDOQI) cardiovascular guidelines recommended that nephrologists counsel patients to increase PA. Our objective was to ascertain whether nephrologists' counseling practices have changed. Methods: We administered a 30-item survey regarding exercise counseling to nephrologists attending the ASN meeting in 2007. Some questions were adapted from a prior survey administered in 2001 to assess differences in practice patterns compared to 6 years earlier. Results: Participants answered questions regarding opinions and practices relevant to PA $(n=198)$, KDOQI guidelines, self-reported PA, and demographic information $(n=$ 173). Participants were $44 \pm 11$ years of age, $48 \%$ practicing in the USA, and $76 \%$ male. In multivariate analysis, older nephrologists $(\mathrm{OR} ; 95 \% \mathrm{CI})(3.3 ; 1.2-9.0)$ and those more physically active $(5.5 ; 2.0-14)$ were more likely to ask and counsel
\end{abstract}

patients about PA. Opinions associated with less counseling behavior included lack of confidence in ability to discuss PA (0.2; 0.05-0.5). Multivariate comparison to previous respondents $(n=503)$ showed current nephrologists were not asking and counseling more (1.2;0.81-1.8). Conclusion: Despite new guidelines, counseling behavior has not increased. Published guidelines are insufficient to reach younger nephrologists.

Copyright $\odot 2010$ S. Karger AG, Basel

In the general population, a sedentary lifestyle contributes to the development of cardiovascular disease, hypertension and diabetes. Exercise and dietary modification may decrease the risk of developing cardiovascular disease. Recommendations for the general population include engaging in regular physical activity (PA) at a level appropriate to one's capacity, needs, and interest, with a goal of at least 30 min of moderate-intensity PA on most, and preferably all, days of the week [1]. Recent guidelines specifically state that elderly individuals and patients with chronic diseases should also be encouraged to meet the same PA targets, as long as the intensity is adjusted so that it is of moderate intensity for the individual [2], and numerous studies have shown exercise to be safe and beneficial for patients on dialysis [3, 4]. However, despite

\section{KARGER}

Fax +41613061234 E-Mail karger@karger.ch www.karger.com
(C) 2010 S. Karger AG, Basel

$1660-2110 / 10 / 1164-0330 \$ 26.00 / 0$

Accessible online at:

www.karger.com/nec
Cynthia Delgado, MD

UCSF - Veterans Affairs Medical Center, 4150 Clement Street, Box 111J

San Francisco, CA 94121 (USA)

Tel. +1 415221 4810, ext. 2592, Fax +1 4157506949

E-Mail cynthia.delgado@ucsf.edu 
known benefits, patient participation in PA continues to be a problem.

In 2005 the number of patients on hemodialysis in the USA reached a prevalence of 1,016 per million, with an annual increase between the years 2001 and 2005 of $1.7 \%$ [5]. Within the chronic kidney disease population, mortality from cardiovascular disease remains high compared to the general population. A strong association has been demonstrated between physical inactivity and mortality in dialysis patients [6]. Previous studies have found that hemodialysis patients' exercise levels are low despite potential improvements in physical functioning with exercise $[7,8]$. A 2001 evaluation of exercise counseling practices among nephrologists demonstrated that only a small proportion of clinicians were assessing patients' level of PA and counseling to increase activity [9].

As a result of growing evidence suggestive of cardiovascular benefit among the chronic kidney disease population with exercise, the National Kidney Foundation recommended counseling by nephrologists to increase patients' levels of PA in their recently published guideline about management of cardiovascular disease [10]. However, since the publication of the guidelines, there have been no studies evaluating whether there has been a change in counseling practices. We performed a crosssectional survey of nephrologists to ascertain the current rate of PA counseling among practicing nephrologists and to compare current rates of counseling with prior data to determine the extent to which the publication of the Kidney Disease Outcomes Quality Initiative (KDOQI) guidelines has affected practices and opinions regarding exercise counseling.

\section{Methods}

\section{Study Subjects}

We performed a cross-sectional study of nephrologists attending the 40th Annual Meeting and Scientific Exposition of The American Society of Nephrology in San Francisco in October 2007. Five members of the research team approached potential study subjects during conference registration. All nephrologists who care for dialysis patients were eligible. The study was designated as exempt by the Committee on Human Research of the University of California, San Francisco, and permission to conduct the study at the conference was obtained from the American Society of Nephrology.

\section{Study Questionnaire}

The survey instrument consisted of 30 questions. Although no personally identifying information was collected, nephrologists were asked about the nature of their dialysis practice as well as about their own participation in PA. Several questions regarding nephrologists' opinions and practices relating to exercise counseling were adapted from a previous survey conducted at the October 2001 Annual Meeting and Scientific Exposition of the American Society of Nephrology San Francisco [9] to allow for direct comparison. The $2003 \mathrm{KDOQI}$ guideline on PA was provided to participants after completion of the opinion and practices section of the survey [10]. After reading the guideline, nephrologists were asked questions regarding the usefulness of the guideline.

\section{Statistical Analysis}

Participant characteristics were described using mean \pm SD for normally distributed variables and median with 25 th and 75 th percentile for variables that were not normally distributed. Comparisons between US and non-US nephrologists were made using $\mathrm{t}$ tests for continuous variables and $\chi^{2}$ tests for categorical variables. Nephrologists who reported they 'always or almost always' ask dialysis patients about PA were treated as the counseling group. Level of agreement with each opinion was ascertained on a 5-point scale from 'strongly disagree' to 'strongly agree' and then truncated to a binary variable by combining 'strongly agree' and 'agree' into a single category indicating agreement for the purpose of comparing the counseling group to the non-counseling group. Univariate analysis was performed to determine significant predictors of counseling for use in multivariate analysis. Multivariable logistic regression was performed to determine which characteristics and opinions were independently associated with counseling behavior among nephrologists.

Data collected from the cohort was analyzed to determine current practice behaviors. To evaluate change in practice patterns, the current cohort was compared to the previous (2001) cohort by combining both groups into a single regression analysis. A variable was created for study cohort (time period), and multivariable regression was used to determine whether counseling behavior had increased since the publication of the guidelines explicitly recommending counseling. All statistical analyses were performed in STATA Version 10.0 (College Station, Tex., USA). We considered a two-tailed $\mathrm{p}<0.05$ to be statistically significant.

\section{Results}

A total of 204 participants responded to the survey, but 4 surveys were excluded because of ineligibility. (Three participants were retired; one participant was a not a nephrologist.) 198 practicing nephrologists responded to questions regarding their opinions and practices relevant to PA. 173 of the 198 participants also responded to questions regarding the KDOQI guidelines, self-reported PA levels, and demographic information, of which $48 \%$ identified themselves as practicing in the USA (table 1). NonUS respondents represented 36 countries around the world. The majority of international respondents were from six countries (Canada, UK, Germany, India, France and Japan), each of which had at least 5 respondents. Of those completing the demographics portion of the survey $(n=173)$, the majority were younger than 50 years of age 
Table 1. Descriptive characteristics of study participants

\begin{tabular}{llll}
\hline & $\begin{array}{l}\text { Overall } \\
(\mathrm{n}=173)\end{array}$ & $\begin{array}{l}\text { US nephrol- } \\
\text { ogists }(\mathrm{n}=83)\end{array}$ & $\begin{array}{l}\text { Non-US nephrol- } \\
\text { ogists }(\mathrm{n}=90)\end{array}$ \\
\hline Median age & $42(34,53)^{1}$ & $38(33,53)^{1}$ & $42(37,52)^{1}$ \\
Male, \% & 76 & 72 & 78.6 \\
Median length of practice, years (mean 13.5, SD 10.5) & $10(3,20)^{1}$ & $5(2,18)^{1}$ & $12(5,20)^{1}$ \\
Median number of dialysis patients & $60(30,120)^{1}$ & $35(20,80)^{1}$ & $90(45,150)^{1}$ \\
Percent primary care $(\mathrm{n}=168), \mathrm{p}=0.002$ & & & 11 \\
$\quad$ None & 35 & 21 & 28 \\
$\quad<50 \%$ & 67 & 38 & 47 \\
$\quad>50 \%$ & 72 & 23 & 24 \\
Percent of self-reported level of PA & & 25 & 32 \\
$\quad$ Do not exercise regularly & 25 & 35 & 44 \\
$\quad$ Vigorous ex. $<3$ weeks, moderate ex. $<5$ weeks & 33 & 40 & \\
$\quad$ Vigorous ex. $>3$ weeks, moderate ex. $>5$ weeks & 42 & & \\
\hline
\end{tabular}

Demographic and self-reported PA level available for 173/198 respondents.

${ }^{1}$ Values in parentheses represent the 25 th and 75 th percentile of distribution.

Table 2. Percent agreement with opinion statements

\begin{tabular}{|c|c|c|c|c|}
\hline Percent agreement with statements & $\begin{array}{l}\text { Overall } \\
(\mathrm{n}=198)\end{array}$ & $\begin{array}{l}\text { US } \\
\text { nephrologists } \\
(\mathrm{n}=83)\end{array}$ & $\begin{array}{l}\text { Non-US } \\
\text { nephrologists } \\
(\mathrm{n}=90)\end{array}$ & $\begin{array}{l}\text { Other (unidentified } \\
\text { US vs. non-US) } \\
\text { nephrologists }(\mathrm{n}=24)\end{array}$ \\
\hline $\begin{array}{l}\text { Physical inactivity (sedentary lifestyle) is an important health risk in the } \\
\text { general population }\end{array}$ & 98.5 & 98.7 & 98.8 & 95.6 \\
\hline Increasing PA is beneficial for most people & 99.5 & 100 & 98 & 100 \\
\hline PA is beneficial for patients on dialysis & 100 & 100 & 100 & 100 \\
\hline I am concerned about the risks of exercise in patients on dialysis & 40 & 37 & 47 & 25 \\
\hline $\begin{array}{l}\text { I do not believe that most dialysis patients would increase PA if advised } \\
\text { to do so }\end{array}$ & 56 & 58 & 56 & 50 \\
\hline I do not think dialysis patients are interested in the topic of PA & 35 & 40 & 30 & 35 \\
\hline I do not think exercise is important (or is as important as other issues) & 7.2 & 3.6 & 11 & 4 \\
\hline I do not feel confident in my ability to discuss this topic with patients & 14.7 & 13.25 & 16 & 12.5 \\
\hline
\end{tabular}

(median 42 , 25th percentile 34 , 75th percentile 53), and $76 \%$ were male (table 1). $42 \%$ of participants met the Surgeon General's recommendation of moderate PA more than 5 times per week. There were no differences in level of PA between US and non-US nephrologists. $28 \%$ of US and $55 \%$ of non-US nephrologists reported that they provide primary care to more than $50 \%$ of their patients on dialysis $(\mathrm{p}<0.01)$. The mean length of practice for the entire group was $13.5 \pm 10.5$ years. Overall, nephrologists cared for a median of 60 patients $(30,120)$. Non-US nephrologists cared for more patients than their US counterparts.

The majority of respondents agreed that physical inactivity is an important health risk in the general population (98.5\%) and that increasing activity is beneficial for most people (99.5\%) (table 2). With regard to dialysis patients, while all respondents agreed that exercise was beneficial, $40 \%$ were concerned about the risk of exercise, and more than half believed that dialysis patients would not exercise if advised to do so. The majority of respondents 
Table 3. Core multivariable characteristics associated with counseling

\begin{tabular}{|c|c|c|c|c|c|c|c|}
\hline \multirow[t]{2}{*}{ Predictor } & \multirow[t]{2}{*}{ Categories } & \multicolumn{2}{|c|}{ Ask about levels of PA } & \multicolumn{2}{|c|}{$\begin{array}{l}\text { Counsel the sedentary } \\
\text { to increase PA }\end{array}$} & \multicolumn{2}{|c|}{$\begin{array}{l}\text { Both ask and counsel } \\
\text { on PA }\end{array}$} \\
\hline & & odds ratio & $\mathrm{p}$ value & odds ratio & $\mathrm{p}$ value & odds ratio & $\mathrm{p}$ value \\
\hline \multirow[t]{3}{*}{ Nephrologists' level of PA } & \multirow{3}{*}{$\begin{array}{l}\text { Infrequent } \\
\text { Vigorous }<3 / \text { weeks or } \\
\text { moderate }<5 / \text { weeks } \\
\text { Vigorous }>3 / \text { weeks or } \\
\text { moderate }>5 / \text { weeks }\end{array}$} & 1.0 & - & 1.0 & - & 1.0 & - \\
\hline & & 3.94 & 0.008 & 2.10 & 0.09 & 3.30 & 0.021 \\
\hline & & 5.9 & 0.0001 & 2.62 & 0.02 & 5.50 & 0.001 \\
\hline \multirow[t]{2}{*}{ US nephrologists } & Non-US & 1.0 & - & 1.0 & - & 1.0 & - \\
\hline & US & 0.88 & 0.75 & 1.02 & 0.94 & 0.79 & 0.53 \\
\hline \multirow[t]{3}{*}{ Age of nephrologists in years } & $<35$ & 1.0 & - & 1.0 & - & 1.0 & - \\
\hline & $36-54$ & 1.50 & 0.34 & 1.46 & 0.35 & 1.44 & 0.4 \\
\hline & $>55$ & 3.00 & 0.03 & 2.75 & 0.05 & 3.33 & 0.018 \\
\hline \multirow{3}{*}{$\begin{array}{l}\text { Proportion of dialysis } \\
\text { patients who receive primary } \\
\text { care from nephrologists }\end{array}$} & None & 1.0 & - & 1.0 & - & 1.0 & - \\
\hline & $<50 \%$ & 2.18 & 0.12 & 1.46 & 0.14 & 2.03 & 0.16 \\
\hline & $>50 \%$ & 2.23 & 0.11 & 1.74 & 0.08 & 1.88 & 0.20 \\
\hline
\end{tabular}

agreed that exercise was as important as other issues (92.7\%).

In univariate analysis, physician age, level of PA, proportion of dialysis patients for whom the nephrologist provides primary care, and US versus non-US practitioner were the variables found to have the strongest association with counseling behavior. In multivariate analysis, a core model was established using the predictors identified in univariate analysis. In the core model, nephrologists who were older and more physically active were more likely to ask and counsel patients about PA (table 3). Nephrologists older than 55 years of age were 3 times more likely to ask and counsel patients on PA than nephrologists younger than 35 (OR 3.33, p = 0.02). In addition, physicians who met the Surgeon General's recommendations for PA were 5 times more likely to counsel compared to their more sedentary counterparts. There was no difference in counseling behavior among US and non-US nephrologists. Additionally, there was no association between counseling behavior and proportion of patients who received primary care from nephrologists.

After adjusting for the predictors in the core model, nephrologists' opinions (table 3) as modifiable predictors of counseling practices were evaluated (table 4). Participants who were more concerned about the risk of exercise in patients on dialysis were less likely to ask about levels of PA (OR 0.47, $\mathrm{p}=0.04)$. Belief that most dialysis patients would not increase PA if advised to do so was associated with decreased odds of both asking and counseling pa- tients (OR 0.29, p = 0.001). Lack of confidence in the ability to discuss the topic of PA was associated with a lack of counseling behavior (OR $0.21, \mathrm{p}=0.01$ ). Those who felt that exercise was not as important as other issues were also less likely to report counseling behavior (OR 0.09, $\mathrm{p}=0.03$ ). Our core model variables did not change substantively when nephrologists' opinions were included in the models.

After reading the exercise guideline in the survey, $85 \%$ of US and $92 \%$ of non-US nephrologists agreed that guidelines were helpful in clinical practice. However, 57\% disagreed that KDOQI guidelines changed patient management in general. With regard to future practice patterns, $63 \%$ of US and $75 \%$ of non-US physicians agreed that the guideline would change their future patient management. $80 \%$ of participants reported that they considered participation in PA 3-5 times per week to be sufficient.

Despite the general view that guidelines would be likely to change practice, current nephrologists were not asking and counseling more than nephrologists asked the same questions in 2001 before the publication of the guidelines (OR 1.2, $\mathrm{p}=0.35$ ).

\section{Discussion}

In the present study, physicians' age and level of PA were important predictors of counseling behavior. Older nephrologists continue to be more likely to ask and coun- 
Table 4. Multivariate assessment of opinions associated with counseling behavior ${ }^{1}$

\begin{tabular}{|c|c|c|c|c|c|c|c|}
\hline \multirow[t]{2}{*}{ Predictor } & & \multicolumn{2}{|c|}{$\begin{array}{l}\text { Ask about levels } \\
\text { of PA }\end{array}$} & \multicolumn{2}{|c|}{$\begin{array}{l}\text { Counsel the sedentary } \\
\text { to increase PA }\end{array}$} & \multicolumn{2}{|c|}{$\begin{array}{l}\text { Both ask and counsel } \\
\text { on PA }\end{array}$} \\
\hline & & odds ratio & $\mathrm{p}$ value & odds ratio & $\mathrm{p}$ value & odds ratio & $\mathrm{p}$ value \\
\hline \multirow{2}{*}{$\begin{array}{l}\text { I am concerned about the risks of exercise in } \\
\text { patients on dialysis }(n=197)\end{array}$} & Disagree & 1.0 & - & 1.0 & - & 1.0 & - \\
\hline & Agree & 0.47 & 0.04 & 0.56 & 0.10 & 0.54 & 0.09 \\
\hline \multirow{2}{*}{$\begin{array}{l}\text { I do not believe that most dialysis patients would } \\
\text { increase PA if advised to do so }\end{array}$} & Disagree & 1.0 & - & 1.0 & - & 1.0 & - \\
\hline & Agree & 0.34 & 0.004 & 0.29 & 0.001 & 0.29 & 0.001 \\
\hline \multirow{2}{*}{$\begin{array}{l}\text { I do not think dialysis patients are interested in } \\
\text { the topic of PA }\end{array}$} & Disagree & 1.0 & - & 1.0 & - & 1.0 & - \\
\hline & Agree & 0.70 & 0.35 & 0.76 & 0.45 & 0.81 & 0.60 \\
\hline \multirow{2}{*}{$\begin{array}{l}\text { I do not feel confident in my ability to discuss this } \\
\text { topic with patients }\end{array}$} & Disagree & 1.0 & - & 1.0 & - & 1.0 & - \\
\hline & Agree & 0.27 & 0.02 & 0.30 & 0.01 & 0.21 & 0.01 \\
\hline \multirow{2}{*}{$\begin{array}{l}\text { I do not think exercise is important (or is as } \\
\text { important as other issues) }\end{array}$} & Disagree & 1.0 & - & 1.0 & - & 1.0 & - \\
\hline & Agree & 0.23 & 0.08 & 0.37 & 0.16 & 0.09 & 0.03 \\
\hline
\end{tabular}

${ }^{1}$ Controlled for core multivariate characteristics in table 3.

sel patients about PA compared to their younger counterparts. One third of US and one half of non-US nephrologists provided primary care to more than one half of their patients. The provision of primary care was not associated with increased counseling behavior. The $42 \%$ of participants who reported themselves as meeting the Surgeon General's recommendation for PA were 5 times more likely to counsel patients than those who were more sedentary. In addition, several opinions were also associated with the likelihood of counseling. Nephrologists' opinions associated with less counseling behavior included concern about risks of participation and lack of confidence in their ability to discuss the topic of PA. Belief that most dialysis patients would not increase PA if advised to do so was associated with decreased odds of both asking and counseling patients. Those who felt that exercise was not as important as other issues were also less likely to report counseling behavior. These opinions were fairly strong predictors of counseling behavior and may serve as a specific target for education, especially if one considers that lack of confidence in the ability to counsel is a deficit that can be corrected during fellowship training.

The National Kidney Foundation's KDOQI project, which began in 1997 and has since evolved based on the results of ongoing research, has come to be identified as a guide for standardizing and improving the care of dialysis patients worldwide. In the USA, it has also served as the basis for Medicare and Medicaid clinical performance measures. In 2005, cardiovascular practice guide- lines were introduced, and for the first time a guideline related to PA among patients with end-stage renal disease became available. Section II guideline 14 recommends that 'all dialysis patients should be counseled and regularly encouraged by nephrology and dialysis staff to increase their level of physical activity'. The expert panelists further remarked on the importance of identifying patients with unique challenges, such as physical limitations, cardiovascular concerns and motivational limitation, in order to facilitate referral to needed ancillary services (for example to physical therapy or cardiac rehabilitation) to enable patients to follow regimens successfully. Specific activity recommendations include the necessity to refer patients who are severely deconditioned for physical therapy to increase strength and endurance to the point where they are able to adopt the recommended goal level of cardiovascular exercise at a moderate intensity for $30 \mathrm{~min}$ most, if not all, days per week. The guidelines also recommend that patients who are not at a physical level at which the goal can be achieved start PA regimens at very low levels and durations and gradually progress to the recommended level [10].

Despite increased knowledge of the benefits of PA that resulted in the publication of this KDOQI guideline and a 2001 study highlighting counseling deficits, practice patterns have not changed. As research in nephrology continues to produce an enlarging body of evidence that has the potential to enhance clinical practice, information delivery is of crucial importance. The low rate of re- 
ported counseling in our study despite widespread acceptance and awareness of the KDOQI guideline by participants suggests that inclusion of exercise recommendations in the cardiovascular guidelines was not sufficient to change practice. Given that lack of confidence in ability to discuss exercise was related to non-counseling, a more specific set of exercise recommendations, including details of exercise prescription, may serve to increase counseling. This in turn may serve to achieve the ultimate goal of increasing PA among our patients. Recognizing the importance of PA in patients at risk of cardiovascular morbidity and mortality, the American College of Sports Medicine together with the American Heart Association have also set guidelines for PA that provide specific instructions on duration, type of exercise and initiation of exercise categorized by patient population [2]. Unlike KDOQI, where recommendations about exercise are limited to a subsection, the American Heart Association guidelines stand alone and therefore may be less overlooked. Both elderly individuals and patients with coronary artery disease, large subsets of end-stage renal disease patients at higher risk for cardiac events, are included in these guidelines as separate groups. We are behind in making exercise a part of our general practice. As a result of effective guideline-specific directives on exercise, patients with cardiovascular disease are being counseled more routinely by cardiologists about participation in PA, which has translated into improvement in mortality and morbidity [11]. However, only a small proportion of dialysis patients with ischemic heart disease are referred for cardiac rehabilitation. One study reported that only $13 \%$ of dialysis patients were referred for cardiac rehabilitation after coronary artery bypass grafting despite the availability of Medicare reimbursement for these services [12] and despite evidence of a survival benefit among those who did receive cardiac rehabilitation [11]. This disparity among specialists who care for a similar risk group must be addressed. Exploration of other methods of information delivery similar to that of other specialties that recognize the benefit of modifying PA levels should be made.

The results of our study highlight the importance of targeting younger nephrologists. However, the publication of guidelines may be insufficient to reach this target group. A study done among general internal medicine residents demonstrated increased confidence and knowledge about exercise counseling after participating in workshops, which translated into an increase in counseling behavior [13]. Even though the study may have been too short to demonstrate a change in patients' habits, this study was able to clearly improve on the frequency and comfort level of exercise counseling by younger practitioners. To improve on reported lack of confidence in counseling behavior, nephrology fellowship curricula should include similar lifestyle modification training.

We attempted to prevent bias that may be incurred with false reporting of PA and counseling habits by making the survey completely anonymous. Nevertheless, the extent to which participants may have distorted these activities cannot be measured and must be acknowledged as a limitation. However, one would have expected to have found an overestimation of counseling practices if this bias contributed to our findings. Thus, our conclusion that there is insufficient counseling activity is likely to be valid. In addition, if overreporting bias were present, associations between opinions and reported counseling would have been diluted rather than highlighted. In addition, because recruitment to participate was limited to English speakers in the registration area at the conference, and preregistered attendees spent less time in the registration area and may have been less inclined to participate, generalizability of our findings to all clinical nephrologists is limited. A final limitation that must be acknowledged is the possibility that participants who were particularly interested in the topic of exercise were probably more likely to participate in the survey compared to those who were not interested in the topic. Again, such a limitation would have been expected to lead to an overestimation of the amount of counseling occurring rather than underestimation.

\section{Conclusion}

The publication of practice guidelines related to counseling and facilitating PA among dialysis patients does not appear to have affected practice patterns in this study. Overall there was no alteration of physician characteristics associated with counseling compared to previous studies. Future efforts to promote counseling on PA should be targeted towards younger nephrologists and should be more detailed and specific. 


\section{References}

$\checkmark 1$ NIH Consensus Development Panel on Physical Activity and Cardiovascular Health: Physical activity and cardiovascular health. JAMA 1996;276:241-246.

$\checkmark 2$ Nelson ME, Rejeski WJ, Blair SN, et al: Physical activity and public health in older adults: recommendation from the American College of Sports Medicine and the American Heart Association. Circulation 2007;116: 1094-1105.

-3 Mustata S, Chan C, Lai V, Miller JA: Impact of an exercise program on arterial stiffness and insulin resistance in hemodialysis patients. J Am Soc Nephrol 2004; 15:2713-2718.

$\checkmark 4$ Painter P, Carlson L, Carey S, Paul SM, Myll $\mathrm{J}$ : Low-functioning hemodialysis patients improve with exercise training. Am J Kidney Dis 2000;36:600-608.
5 United States Renal Data System, USRDS 2007 Annual Data Report: Atlas of Chronic Kidney Disease and End-Stage Renal Disease in the United States, 2007 (www.usrds. org).

6 O’Hare AM, Tawney K, Bacchetti P, Johansen KL: Decreased survival among sedentary patients undergoing dialysis: results from the dialysis morbidity and mortality study wave 2. Am J Kidney Dis 2003;41:447-454.

7 Molsted S, Eidemak I, Sorensen HT, Kristensen JH: Five months of physical exercise in hemodialysis patients: effects on aerobic capacity, physical function and self-rated health. Nephron Clin Pract 2004;96:c76c81.

$>8$ Johansen KL, Chertow GM, Ng AV, et al: Physical activity levels in patients on hemodialysis and healthy sedentary controls. Kidney Int 2000;57:2564-2570
9 Johansen KL, Sakkas GK, Doyle J, Shubert T, Dudley RA: Exercise counseling practices among nephrologists caring for patients on dialysis. Am J Kidney Dis 2003;41:171-178.

$>10$ K/DOQI Clinical Practice Guidelines for Cardiovascular Disease in Dialysis Patients. Am J Kidney Dis 2005;45:16-153.

11 Kutner NG, Zhang R, Huang Y, Herzog CA: Cardiac rehabilitation and survival of dialysis patients after coronary bypass. J Am Soc Nephrol 2006;17:1175-1180.

12 Huang Y, Zhang R, Culler SD, Kutner NG: Costs and effectiveness of cardiac rehabilitation for dialysis patients following coronary bypass. Kidney Int 2008;74:1079-1084.

13 Eckstrom E, Hickam DH, Lessler DS, Buchner DM: Changing physician practice of physical activity counseling. J Gen Intern Med 1999; 14:376-378. 